$$
\text { Pontifícia Universidade C Católica }
$$

JOSÉ JOÃO DE CARVALHO

\title{
A FORMAÇÃO DE PALAVRAS NA LÍNGUA PORTUGUESA: UM ESTUDO DA FUSÃO VOCABULAR NA OBRA DE MIA COUTO
}

\section{Dissertação de Mestrado}

Dissertação de Mestrado apresentada como requisito parcial para obtenção do grau de Mestre em Letras do Departamento de Letras da PUC-Rio como parte dos requisitos parciais para obtenção do título de Mestre em Letras.

Orientadora: Profa. Margarida Maria de Paula Basilio 


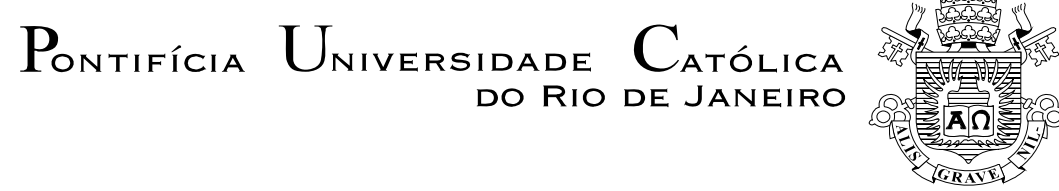

JOSÉ JOÃO DE CARVALHO

\section{A FORMAÇÃO DE PALAVRAS NA LÍNGUA PORTUGUESA: UM ESTUDO DA FUSÃO VOCABULAR NA OBRA DE MIA COUTO}

Dissertação apresentada como requisito parcial para obtenção do grau de Mestre pelo programa de PósGraduação em Letras do Departamento de Letras do Centro de Teologia e Ciências Humanas da PUC-Rio. Aprovada pela Comissão Examinadora abaixo assinada.

Profa. Margarida Maria de Paula Basilio Orientadora Departamento de Letras - PUC-Rio

Profa. Helena Franco Martins Departamento de Letras - PUC-Rio

Prof. Carlos Alexandre Victorio Gonçalves Universidade Federal do Rio de Janeiro - UFRJ

Prof. Paulo Fernando Carneiro de Andrade Coordenador Setorial do Centro de Teologia e Ciências Humanas - PUC-Rio

Rio de Janeiro, de de 
Todos os direitos reservados. É proibida a reprodução total ou parcial do trabalho sem autorização da universidade, do autor e da orientadora.

\section{José João de Carvalho}

Graduou-se em Letras, no curso de Português e respectivas Literaturas, em 1997, pelo Centro de Ciências Humanas e Letras da Universidade Federal do Piauí.

Ficha catálográfica

Carvalho, José João de

A formação de palavras na língua portuguesa : um estudo da fusão vocabular na obra de Mia Couto / José João de Carvalho ; orientadora: Margarida Maria de Paula Basilio. - 2008.

78 f. ; $30 \mathrm{~cm}$

Dissertação (Mestrado em Letras) - Pontifícia Universidade Católica do Rio de Janeiro, Rio de Janeiro, 2008.

Inclui bibliografia

1. Letras - Teses. 2. Morfologia. 3. Léxico. 4. Inovação lexical. 5. Cruzamento vocabular. 6. Fusão vocabular. I. Couto, Mia. II. Basilio, Margarida Maria de Paula. III. Pontifícia Universidade Católica do Rio de Janeiro. Departamento de Letras. IV. Título. 


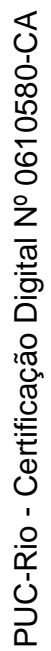

Dedico esta dissertação aos meus pais,

Orlando e Geralda Carvalho. 


\section{Agradecimentos}

Agradeço a Deus por tudo;

Agradeço à minha família pela compreensão nos momentos de ausência;

Agradeço ao CESB/ICSH que me oportunizou a realização deste projeto pessoal;

Agradeço à minha orientadora, Profa. Margarida Basilio, pela dedicação e pelo carinho para com esta pesquisa;

Agradeço às professoras Maria das Graças Pereira, Maria do Carmo Oliveira, Helena Martins, Violeta Quental, Letícia Corrêa e Lúcia Pacheco pelo apoio recebido para este mestrado;

Agradeço aos meus sobrinhos, Jacqueline, Janice e Eudes pela digitação. 


\title{
Resumo
}

Carvalho, José João de; Basilio, Margarida Maria de Paula. (Orientadora). A formação de palavras na Língua Portuguesa: um estudo da fusão vocabular na obra de Mia Couto. Rio de Janeiro, 2008. 78p. Dissertação de Mestrado Departamento de Letras, Pontifícia Universidade Católica do Rio de Janeiro.

Este trabalho investiga a fusão vocabular como um processo de formação de palavras. Inicialmente, conceitua-se palavra em alguns modelos lingüísticos com o objetivo de se encontrar uma definição que inclua formações compostas de dois vocábulos para um único referente. Em seguida, são abordadas as diversas proposições acerca da composição em português, desde a visão tradicional até propostas vinculadas a teorias lingüísticas mais recentes. Posteriormente, é apresentado o cruzamento vocabular na visão de alguns estudiosos, e, a partir de suas considerações teóricas, confronta-se a composição e a fusão vocabular. A parte de análise de dados é feita com um corpus de 106 inovações lexicais, selecionadas na obra do escritor Mia Couto. Como resultado da análise, adota-se a denominação de fusão vocabular para todas as formações sobrepostas que, normalmente, são classificadas por outros estudiosos como cruzamento vocabular. Os resultados da análise revelam a grande produtividade da fusão vocabular como processo de formação de palavras em português, não apenas na modalidade oral, em que os cruzamentos vocabulares são frequentemente atestados, mas também na língua escrita literária. A análise efetuada demonstra a adequação do conceito adotado, segundo o qual a fusão vocabular é um processo sistemático de predicação expressiva de um vocábulo por outro que apresente propriedades fonológicas compatíveis para a efetuação do processo.

\section{Palavras-chave}

\author{
Morfologia - Léxico - Inovação lexical - Cruzamento vocabular - Fusão \\ vocabular - Mia Couto.
}




\section{Abstract}

Carvalho, José João de; Basilio, Margarida Maria de Paula. (Advisor). Word formation in Portuguese: a study of lexical blends in Mia Couto. Rio de Janeiro, 2008. 78p. MSc. Dissertation - Departamento de Letras, Pontifícia Universidade Católica do Rio de Janeiro.

This work investigates the process underlying lexical blend formation. At first, we examine the concept of word in some linguistic models in order to find a definition which would accommodate compounding. Next, we present an overview of morphological and lexical compounding in Portuguese, including both traditional descriptions and those related to more recent linguistic theories. Then, the notion of lexical blend is introduced, according to the definitions presented by specialists in Portuguese Word Formation, and the traditional notion of lexical blend is confronted with the concept of lexical fusion. We then proceed to the analysis of a corpus of 106 occurrences of lexical innovation, selected from the work of the writer Mia Couto. The results of the analysis support the adoption of the concept of lexical fusion for all superposed constructions which are traditionnaly viewed as standard lexical blend cases. Our results also reveal the significant productivity of lexical fusion as a wordformation process in Portuguese, both in speech, where it had already been attested, and in written literary language. The analysis shows the adequacy of the concept of lexical fusion, defined as a systematic process of expressive predication of a word by another word whose phonological properties permit the felicitous operation of the process.

\section{Keywords}

Morphology - Lexicon - Lexical Innovation -Lexical blend -Lexical Fusion Mia Couto. 


\section{Sumário}

1. Introdução 11

1.1. Objetivo geral específico 11

1.2. Pressupostos teóricos e metodologia 12

1.3. Organização do trabalho 12

2. Palavra: uma breve introdução 14

2.1. O conceito de palavra 14

2.2. Palavra composta: sua formação 18

2.2.1. Estruturação das Palavras Compostas 18

2.2.2. Abordagem Tradicional sobre Palavra Composta 22

2.2.3. Abordagem de Transição: Bechara (2003) 24

2.2.4. Abordagens Estruturalistas sobre Palavra Composta 29

2.2.5. Abordagens Recentes sobre Palavra Composta 32

2.2.5.1. As Propostas de Sandmann 32

2.2.5.1.1. Compostos vernáculos e compostos não-vernáculos 32

2.2.5.1.2. Compostos copulativos e determinativos 33

2.2.5.1.3. Compostos endocêntricos e compostos exocêntricos 35

2.2.6. Basilio (2000a): a composição descritiva e figurativa 36

3..Cruzamento Vocabular: introdução 40

3.1. Cruzamento Vocabular: a primeira proposta de Sandmann 42

3.2. Cruzamento Vocabular: a segunda proposta de Sandmann 43

3.3. Basilio (2005): a distinção entre cruzamento vocabular e fusão vocabular $\quad 44$

3.4. A proposta de cruzamento vocabular de Gonçalves \& Almeida (2006) 47

4. A formação de palavras em onbras literárias: a estilística e o autor 52

4.1. Análise de fusão vocabular em Mia Couto 60

$\begin{array}{ll}\text { 5. Conclusão } & 68\end{array}$

6. Referências Bibliográficas 70

7. Apêndice 75 


\section{Lista de abreviações das obras literárias consultadas}

Grande Sertão: Veredas

Tutaméia

Sagarana

Primeiras Estórias

Migüilim e Manuelzão

Terra Sonâmbula

Estórias Abensonhadas

Mar me quer

Cronicando

Vinte e Zinco

Cada homem é uma raça

Último vôo do flamingo

A varanda do frangipani

Contos do nascer da terra

Um rio chamado tempo, uma casa chamada terra
GSV

$\mathrm{T}$

$\mathrm{S}$

PE

MM

TS

EA

M

C

VZ

$\mathrm{CH}$

UV

$\mathrm{VF}$

CNT

RT 


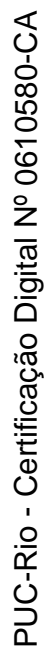

As palavras têm canto e plumagem.

João Guimarães Rosa 